Janardana, J.A.B., Samaraweera, A. and Jayasena, H.S., 2021. Suitability of ICTAD formula and CIDA price indices to calculate the amount of price escalated in construction projects. In: Sandanayake, Y.G., Gunatilake, S. and Waidyasekara, K.G.A.S. (eds). Proceedings of the $9^{\text {th }}$ World Construction Symposium, 9-10 July 2021, Sri Lanka. [Online]. pp. 505-515. https://doi.org/10.31705/WCS.2021.44. Available from: https://ciobwcs.com/papers/

\title{
SUITABILITY OF ICTAD FORMULA AND CIDA PRICE INDICES TO CALCULATE THE AMOUNT OF PRICE ESCALATED IN CONSTRUCTION PROJECTS
}

\author{
J.A.B. Janardana ${ }^{1}$, A. Samaraweera ${ }^{2}$ and H.S. Jayasena ${ }^{3}$
}

\begin{abstract}
Price fluctuation is a significant risk factor, in every construction project market. It is unavoidable and difficult to forecast. However, it is often argued that there is a difference between the amount calculated with the CIDA price fluctuation formula method and the actual price fluctuation. Therefore, the aim of this research is to investigate the industry opinion on whether there is a difference between price escalations calculated using the CIDA price fluctuation formula and actual price fluctuation.

A qualitative research approach was selected to achieve the aim of this research. Through a broad study of literature, it was identified the most critical factors which affected actual price fluctuation deviation. Meanwhile, semi-structured interviews were carried out to identify the reasons affecting fluctuation difference by analysing the data, which was used, and comparing the opinions given by the interviewees.

The data was analysed using context analysis. The results of the research confirm that. there is a difference between the amount of price escalation using the ICTAD price fluctuation formula and the actual being used. The main reason behind this difference is the less accuracy of cost indices. To improve the accuracy of the results of this formula, appropriate data collection using an appreciate sample of contractors in producing price indices is recommended as the main.
\end{abstract}

Keywords: CIDA; Indices; Price fluctuation.

\section{INTRODUCTION}

Due to major characteristics; large, heavy and expensive products of the construction industry differ in many ways from other industries. As a result, the higher involvement of many types of inputs is essential for the substantial completion of projects. The gradual increase in the price indices expos a rising cost of construction inputs in the domestic industry mainly, due to inflation (Weddikkara and Devapriya, 2001).

\footnotetext{
${ }^{1}$ Department of Quantity Surveying, Sri Lanka Institute of Information Technology, Sri Lanka, bihara.j@sliit.lk

${ }^{2}$ School of Natural and Built Environments, University of South Australia, Australia, aparna.samaraweera@unisa.edu.au

${ }^{3}$ Department of Building Economics, University of Moratuwa, Sri Lanka, suranga@uom.lk
} 
Price fluctuation is a "percentage increase between the initial base estimate and the final achieved cost" (Dawood and Bates, 2000).

The principle causes of escalation are inflation, market conditions, taxes, other government actions, schedule extension, allocation of risk, and national and international events such as an outbreak of war (Hanna and Blair, 1993). In addition, the construction industry is largely affected by price fluctuation due to its inheritable characteristics such as costliness, long duration of the production process, heterogeneous nature, unique output, and the differences of the other industries. However, Hanna and Blair (1993) stated the main effect of escalation to the construction industry is the risk and uncertainty regarding the project cost. It will also affect financial difficulties for both contractors and the client and ultimately may delay the delivery of the project.

In the past, particularly, most of the contracts were arranged on a fixed/firm price basis. Cook (1991) states that fixed-price contracts where the prices contained in the contract bills are not adjusted to take account of fluctuations in the cost of labour and materials. In those situations, contractor has to bear up the risk of all price fluctuations. More work has been carried out on this basis, with the steady inflationary periods contractors were reluctant to offer firm price contracts since they cannot predict future price fluctuation. Therefore, the variation clause was introduced to the contract in the condition of contract to overcome this difficulty. This embodies after the contract was signed the net amount of such fluctuation would be added to or deducted from the contract sum, when the event of a fluctuation in prices of materials, labour to name a few. Therefore, depending on the contractual agreement the "fluctuation may be recoverable or non-recoverable in whole or in part" (Dawood and Bates, 2000 cited Liyanage, 2005). It creates two different arrangements of contract, which are fixed price/firm price contract and the fluctuating price contract.

There are two broad ways of calculating price fluctuation that compensate the parties to the contract in fluctuation; namely the traditional method and formula method. The traditional method is a full reimbursement method and on the other formula method is a partial reimbursement method (Jayasinghe et al., 2015). However, it is often argued that Sri Lankan contractors are not satisfied with the way price fluctuation is paid with the formula method and the way of calculating methods of input percentages used by Sri Lankan professionals due to the difference of actual price fluctuation and the amount reimbursed from formula method.

Therefore, this research was conducted to prove the fact whether there is a difference between CIDA price fluctuation formula and the actual price fluctuation and the reasons for this difference and to improve the accuracy of the CIDA price fluctuation formula.

\section{LITERATURE REVIEW}

As cited by Ashworth (2005) price fluctuations are considered as an allowance allocated for cost inflation for a particular project that can or cannot be reimbursed by the contractor according to the contract. This amount depends according to the amount of inflation that exists on and during the contractual period.

This further can be stated as the increasing percentage of the initial estimate and the final cost achieved (Dawood and Bates, 2000). As defined by the study by fellows et al. (Suraweera, 2001) fluctuations can be recoverable or non-recoverable. Escalations can be 
explained as the increase of the cost of the construction elements during the construction which are necessary for the original contract (Hanna and Blair, 1993).

As investigated by the previous studies it is proved that price fluctuations are a risky factor whereas it is difficult to avoid and predict. It is not considered to be the fault of the parties involved with the contract or the client. Due to the inflation in the economy in Sri Lanka Price fluctuations can be commonly observed as this is a developed country.

\subsection{Reasons FOR Price FluCtuation}

Most of the prices in the current industry are changing and increasing due to reasons which are globally affected such as inflation, technological changes, and oil price increase (Sendooran, 2005). Price escalations vary from a project to another as per the requirement of the construction elements and method of construction. One of the previous research done by Hanna and Blair (1993) concluded that the major reasons which cause escalations are market conditions, government actions such as taxes, inflation, extension of schedules, and risk allocation. Characteristics of the construction industry such as long duration, costliness and unique output unlike the other industries cause price fluctuations. Hanna and Blair (1993) further stated that the major effect caused by escalations is the uncertainty to the project costs and risks to the construction project. This will eventually cause financial problems for the client and the contractor both and may cause delays in the delivery.

\subsection{Dealing With Price Fluctuation Contracts and Price FLUCTUATIONS}

As stated by Franks (1984), it is unrealistic that the contractors can submit a fixed price for major contracts in which the works need to be carried out for over of years ahead. Hence it is necessary to submit price fluctuations or variations in the tender stage. As an effect of deciding the markup allocated for the price fluctuations, it is understandable that the risk will be taken by the client.

Fluctuating contracts contain provisions for changes and reimbursement of additional costs for labour, plant and materials (Ramus, 1981). Cook (1991) concluded that the prices in firm price contracts are adjustable in the account of fluctuations after the tender date.

In fluctuating tenders, the agreed contract sum can be changed as the cost of resources is changed before the beginning of the job (Brook, 1998). Hence different methods are used in the construction industry in Sri Lanka, mainly it is categorized into two parts:

1. Price fluctuation and reimbursement method - contractor can recover the price fluctuation of materials, plant and labour

2. Price fluctuation compensation model - this may not be the actual price fluctuation. It only includes a cost or compensation for the additional costs incurred due to price increase in materials, labour and plant by the main contractor.

When comparing the above two methods the most adaptable method to be used can be considered as the reimbursement method than the other method which is the compensation method. But in the practical context, it is difficult to use as it is a time- 
consuming and costly method. In the current construction industry, the compensation method is used in Sri Lanka.

\subsection{Contribution of Price Fluctuation Clause in Standard BIDDING DOCUMENT}

In the standard bidding document second edition in 2007 under the procurement of work in major contracts, clause 13.7 states about dealing with price fluctuations as in adjustment of change in cost. Further, it states that the prices computed according to the given formula in the sub-clause with respect to rise and fall in the cost of labour, material, plant and other works and shall be deducted or added for the payment of the contractor.

The adjustments of payment certificates concerning the changes in legislation and cost can be determined according to the ICTAD formula. Under a special circumstance, the contractor will have to pay an additional amount and no adjustments on the contract price relevant to the fluctuations can be made. In any circumstances, if the contractor fails to complete the construction work within the given time as specified in clause 17 or 28 and the price adjustments can be made for the performed work using the current indices.

\subsection{Price Fluctuation Recovery Methods Practiced in the CONSTRUCTION INDUSTRY}

There are methods, which can be used to recover or reimburse the price fluctuations for the client or the contractor in any case of price increase or decrease. Mainly there are two methods i.e., through the Traditional/Reimbursement method or the Formula/ Compensation method.

The traditional and reimbursement method can be used based on the cost incurred and the formulae method can be used to value the works executed (Ahenkorah, 1994). The main objective of the formulae method is to calculate the prices which will compensate for the loss incurred. None of the attempts are made to formulate or price the actual amount of the fluctuation or loss that occurred. The amounts recovered by the formulae method are different from the sums recovered by the traditional methods. Therefore, it is believed that the traditional method is superior to the formula method (Ramus, 1981).

\subsection{Procurement Guidelines}

As per the procurement guidelines (2006), the price adjustments for the works exceeding a period of three months and the price variation formula in the Sri Lankan rupee component is included in the contract agreement and bidding document. The price variation formulae formulated by the CIDA shall be used.

For foreign funding projects, it is necessary to understand the requirement and the price adjustments shall be made by foreign currency.

\subsection{CIDA Formula Method FOR Price Fluctuation}

\subsubsection{Simplified Formula - CIDA}

The following formula has been formulated for the projects with the contract sum of less than Rs. 10 million. 


$$
F=0.869\left(V-V_{n a}\right) \frac{x\left(I_{t c}-I_{t b}\right)}{I_{t b}}
$$

Where; $\mathrm{V}=$ value of the work completed during the specified period, $\mathrm{V}_{\mathrm{na}}=$ nonadjustable element value, $I_{t c}=$ Current composite index for the type of work published by CIDA, $\mathrm{I}_{\mathrm{tb}}=$ Base composite index for the type of work published by CIDA.

In ICTAD simplified formula standard benefits can be gained as this a standard method and also introduces a number of composite index for inputs instead of indices, therefore, usage of this formula has been simple. Also, in practice consultants may approve the full claim as there are fewer uncertainty factors. Also, complex calculations can be avoided by using this formula. These are the major advantages of this ICTAD simplified formula method.

On the other hand, the composite index is to be considered as an average value of each input and therefore it will not be the actual index. This is a major disadvantage. In addition, as per the definition, some projects may not fall into any category as this can be used for contracts with a contract sum of less than 10 million.

\subsubsection{CIDA formula}

CIDA formula is the most prominent and adequate method in the Sri Lankan development industrial practice.

This formula has been developed for contracts exceeding Rs 10 million of the contract value.

$$
\mathbf{F}=\frac{0.966\left(\mathrm{~V}-\mathrm{V}_{\mathrm{na}}\right)}{100} \sum_{\substack{\text { All } \\ \text { Inputs }}} \frac{\mathbf{P}_{\mathrm{v}}\left(\mathbf{I}_{\mathrm{v}}-\mathbf{I}_{\mathrm{vb}}\right)}{\mathbf{I}_{\mathrm{xb}}}
$$

Where; $\mathrm{F}=$ Price adjustment for the period, $\mathrm{I}_{\mathrm{x}}=$ Price Index for Input $\mathrm{X}$, publishby CIDA, $\mathrm{I}_{\mathrm{xb}}=$ Base forinput, publishby CIDA, $\mathrm{I}_{\mathrm{xc}}=$ Current for input $\mathrm{X}, \mathrm{M}_{\mathrm{c}}=80 \%$ of the Invoiced Value of materials used for permanent works on current valuation, $\mathrm{M}_{\mathrm{p}}=80 \%$ of the invoices Value of. material used for permanent works on previous valuation, $\mathrm{P}_{\mathrm{x}}=$ Percentage cost contribution of input $\mathrm{X}, \mathrm{V}=$ Valuation of work done during the period concerned, $\mathrm{V}_{\mathrm{c}}=$ Cumulative Value of work done up to current claim, $\mathrm{V}_{\mathrm{p}}=$ Cumulative Value of work done up to previous valuation, $\mathrm{V}_{\mathrm{na}}=$ Value of Non-adjustable Element.

This CIDA formula price fluctuation recovery method is a standard procedure. Therefore, the claims calculated from this formula can be checked easily with less disputes. Also due to few uncertainty elements are involved the claims can be approved by the consultant.

This method also has disadvantages and can be listed down as follows:

1. Fluctuations are restricted to inputs such as plants and equipment, materials and labour as published in the bulletin.

2. It is problematic and complex to calculate input percentages.

3. Fluctuation is restricted to several inputs like material plant \& equipment and labour published from the bulletin. 
4. Inaccurate presumption like the equivalent circulation of data sources however out the agreement span is utilized to compute the variance effectively.

5. Indices are produced by considering the whole country not the location of projects (Suraweera, 2001).

\subsection{FACTORS THAT AFFECT THE EFFECTIVENESS OF THE CIDA FORMULA}

This formula is developed by the CIDA for the calculation of price fluctuation in development contracts has been endorsed by the cabinet of the government for national appropriation. Along these lines, it is a standard technique prescribed by the administration because of its innate attributes. As stated by Chandrasena (2005), one of the salient features of the formula method is that contract price adjustments are determined by the network done value executed or performed during that specific period and the average fluctuation rate. Further, he also has stated that there are two vital fundamentals for an effective application of the ICTAD formula: i.e.;

1. Reliable price indices

2. Accurate input percentages

The price indices are published by the CIDA monthly bulletin. Input percentages are ascertained by the expert at the offering stage and it is made reference to in the delicate report. Therefore, there are no other exceptional necessities to process the change cost looking at the other technique. In addition, it is a speedier and simple strategy for occupied amount surveyors. Therefore, the regulatory expense would be diminished drastically. Facilitate installment for increment would be made much rapidly at the season of every valuation for the temporary worker. Due to these inherent characteristics of the CIDA formula, it turned out to be the most predominant and generally used technique in the Sri Lankan construction industry.

\section{RESEARCH METHODOLOGY}

Initially, literature survey was conducted by referring Books, journal articles, e-journals, e-articles, conference papers, publications and previous unpublished dissertations to identify the concept of inflation risk, price fluctuation, price fluctuation recovery method in construction projects and its applications. It was identified all the breadth and depth factors that affect price fluctuation, CIDA price fluctuation and advantages and disadvantages of it.

Considering the in-depth investigation required in this study, a qualitative research approach was selected for this study. Data were collected using semi-structured interviews. Interviewees were selected using the non-probability sampling technique. Semi-structured interviews were conducted among quantity surveyors among contractor quantity surveyors and professionals at CIDA that have immense knowledge in ICTAD price fluctuation formula. Ten quantity surveyors from various contractor organizations, who are using the CIDA price fluctuation formula and five professionals, who are working at Construction Industry Development Authority (CIDA) were selected for the qualitative survey of this research. The selected professionals from CIDA were between 15-25 years of experience in the industry and the contractor quantity surveyors ar between 07-31 years of experience and five were charted quantity surveyors, on Director/Principal Quantity Surveyor and the rest were Graduate Quantity Surveyors. Th interviewees were questioned about their opinion on the suitability of using the CID. 
formula for calculating price escalation and according to their experience, the accuracy of the outcome of using this formula. Next, they were questioned about the reasons for the difference of actual price fluctuation and the fluctuation amount calculated through the ICTAD formula and recommendations to improve the outcome of using such formula. The data collected were analysed using code-based content analysis.

\section{ANALYSIS AND RESEARCH FINDINGS}

\subsection{INTERVIEWS WITH CIDA PROFESSIONALS}

Interviews with CIDA professionals were analysed under three themes.

\subsubsection{Difference between Actual Price Escalated Amount and Compensated Price Escalated Amount}

With the literature found contractors are dissatisfied with compensated price escalated amount paid. They argue that in the real situation, the actual price escalated amount differs than that in the compensated price escalated amount. This fact was proved by the CIDA expertise. The reason behind this is that the formula has been developed assuming that the work done on the project is equal whereas in the actual situation it is not. Therefore, it will lead to a difference of 5-10\%. However, as it is compensation the accumulated value will be the same $5-10 \%$ tolerance.

\subsubsection{Methods which CIDA can help the Accuracy of Compensating the Contractor when using the ICTAD Price Fluctuation Formula}

As the possible methods, the experts suggested that if CIDA could publish more accurate indices and this will lead to increase the accuracy of compensating the contractor when using the ICTAD formula.

CIDA collects data from contractors to make indices. Even though it is the best solution this has not been practical as the data collected from the contractor's side is less accurate.

Further, the accuracy of Indices is low due to the location changes.

\subsubsection{Accuracy of Cost Indices}

As identified from the literature survey, cost indices are important when using the ICTAD fluctuation formula. If these cost indices are not accurate there will be a difference in the outcome from the ICTAD price fluctuation formula. According to the expertise, the data collection method has to improve. This is due to the inaccuracy of data as the price of inputs used to prepare are average prices out of many number suppliers. The data is collected from many different suppliers, but the suppliers do not give accurate data or sometimes they do not give this data.

Prices of materials are fluctuating rapidly. Most of the material prices are collected directly from the supplier on the other hand for materials such as Bitumen the data is collected from Ceylon Petroleum Corporation. There is some decanted bitumen which is also used they are collecting prices from the private suppliers which have become the most difficult part because in some months they are not producing these. Even though it is a very small amount, it is also affected when preparing indices.

The other item is labour. Normally, labour wages are collected from the contractors. There is a list of contractors but only a few people are providing information. Furthermore, labour wages are not changed every month, unlike materials. Most of the 
contractors provide incorrect information and CIDA individuals have to analyse this and have to stop getting information from these contractors. This has become a major issue as a contractor to contractor, the range of wages are different. For example, for unskilled labours, one contractor may pay LKR 2,000 and another contractor may pay LKR 1,000. CIDA individuals will have to stop one contractor and then they have to get another contractor in the same range. The same theory applies to suppliers. It was recommended that the industry should provide accurate information to publish correct indices. Therefore, it is important to develop a procedure to get real data.

\subsection{INTERVIEWS WITH CONTRACTORS' QUANTITY SURVEYORS}

Interviews with contractor's quantity surveyors were analysed under twelve themes.

\subsubsection{Widely used Price Fluctuation Formula}

It was revealed the CIDA formula and FIDIC formula are widely used methods for price fluctuation. Generally, the FIDIC formula is used for foreign-funded projects and the CIDA formula is used for location projects. The main advantage of using the CIDA formula in Sri Lanka is that it is the standard method to recover price fluctuations, it is in industry practice, and all the data relevant to this can be easily obtained. Therefore, the claims calculated from this formula can be checked easily with fewer disputes. However, due to few uncertainty elements are involved the claims can be approved by the consultant.

\subsubsection{Satisfaction of ICTAD Price Fluctuation Formula}

It was revealed the majority of contractors' Quantity Surveyors were not completely satisfied. This is due to the inaccuracy of the basis which takes to create indices monthly bulletin. There are lapses in collecting these data to develop indices. It was further revealed that sometimes there is inclusive of taxes to the price of materials, which directly affects the output of the ICTAD formula.

At the same time, it was revealed that there are only one price indices for all heavy machinery. However, the rates between machinery have a huge difference. Therefore, the price fluctuation can be varied.

\subsubsection{Advantages in using the CIDA Formula instead of other Formulae (JCT, FIDIC)}

It is difficult to apply JCT and FIDIC in the Sri Lankan context. FIDIC formula is not currently practicing in Sri Lanka but it has been used a few periods back. Even if the FIDIC formula is used as a form of contract, the ICTAD price fluctuation formula is amended. As CIDA is in the Sri Lankan context it is an advantage because required indices can directly use in the formula.

\subsubsection{Advantages Faced as a Contractor by using ICTAD Formula}

The main advantage when using this formula is time-saving and no advanced knowledge is needed; simple calculation. There is a positive impact on the financial side for contractors, which enables them to claim price variance monthly because they have all the required data. 


\subsubsection{Proposals to Improve the Process of Calculating the Inflation Amount}

It is required to increase the accuracy of the bulletin by considering location, therefore; it was suggested to prepare indices separately for different districts as location indices. The main drawback with the indices is that they are prepared on a national basis disregarding the regional variations of prices of inputs, thus gives inaccurate fluctuation calculations. It is also required to develop this ICTAD formula and increase the accuracy of collecting data. Further, separate indices for every heavy machinery should be provided.

\subsubsection{Issues faced in using the Formula}

There is an issue in the timely issuing of the CIDA bulletin. This is because in Sri Lanka most of the contractors are submitting the Interim Payment Application on the $10^{\text {th }}$ of every month. Sometimes bulletin is not issued at this time and contractors will have to use the previous month's bulletin.

\subsubsection{Difference between Actual Price Escalated Amount and Compensated Price Escalated Amount}

There is a price difference between the actual price escalated amount and compensated price escalated amount. According to experts, CIDA is taking an index as a composite price. They take prices from 3, 4 sources. A contractor must have used a different source and given details about another source.

\subsubsection{Strategies to Improve the Process of Price Escalation Amount Paid}

Overall strategies gathered from the interviews are presented below.

- Appropriate data collection with proper contractors - if this method is followed then the accuracy of cost indices will be high. As cost indices are directly affecting to result from the ICTAD fluctuation formula then the reimbursement will also be accurate. And this will result in a positive way for the contractor.

- Issue the monthly bulletin at least 5 days earlier - If this method is carried out then the contractor can use the same month bulletin for the same month of Interim Payment Application. Even if it is a small amount change in indices in different months, it will result in relatively large amounts.

- Proper calculation method or regional indices should be introduced - since locational price differences are unavoidable - Since the indices are prepared on national basis disregarding the regional variations of prices of inputs, thus gives inaccurate fluctuation calculations. Prices of materials, such as sand and rubble and aggregate, is highly varying in every regional area. If regional price indices are prepared, then the reimbursement from the ICTAD price fluctuation formula will be highly accurate.

- A recognized institute or regulatory body should maintain long term price records - to calculate base indices and current indices to analyse - If a recognized body such as International Quantity Surveyors of Sri Lanka can interfere and gather data to build up a database to keep records to calculate base indices and current indices then it will be highly accurate. And those data can be analysed.

- A proper calculation method should be proposed to calculate the work done quantity relevant to each valuation period. 


\subsubsection{Satisfaction on the ICTAD Formula}

The majority of CIDA professionals were satisfied. The main reason behind this is that the no need to keep many records/documents. Less paperwork because the simple calculation is there in this formula and it is time-saving therefore, price fluctuation claim can be calculated within a lesser time duration with the information provided in the interim statement. As this is a standard method over the country to calculate price fluctuation formula it leads to dispute-free environment.

\subsubsection{Proposals to Improve the Accuracy of Indices}

Contractors are the main stakeholders in this process. Therefore, it is important to get data that are more accurate from the stakeholders of the industry. Further, it is required to review the system by discussing with the suppliers, contractors, clients and consultants every year. As the price indices are calculated based on Colombo and Gampaha district price only. Therefore, the sample size must be spread island wide for more accurate price indices.

\subsubsection{Proposals to Improve the Accuracy of the Price Fluctuation Formula}

There are no proposals to improve the accuracy of the price fluctuation formula. If an attempt is given to improve this formula means, this will lead to complications.

\subsubsection{Problems faced when using the ICTAD Formula}

It is supposed to submit interim statements monthly if that does not happen the contractor cannot use the actual indices (indices in the same month cannot be used) which means real fluctuation cannot be matched.

A summary of the key findings is presented in Figure 1.

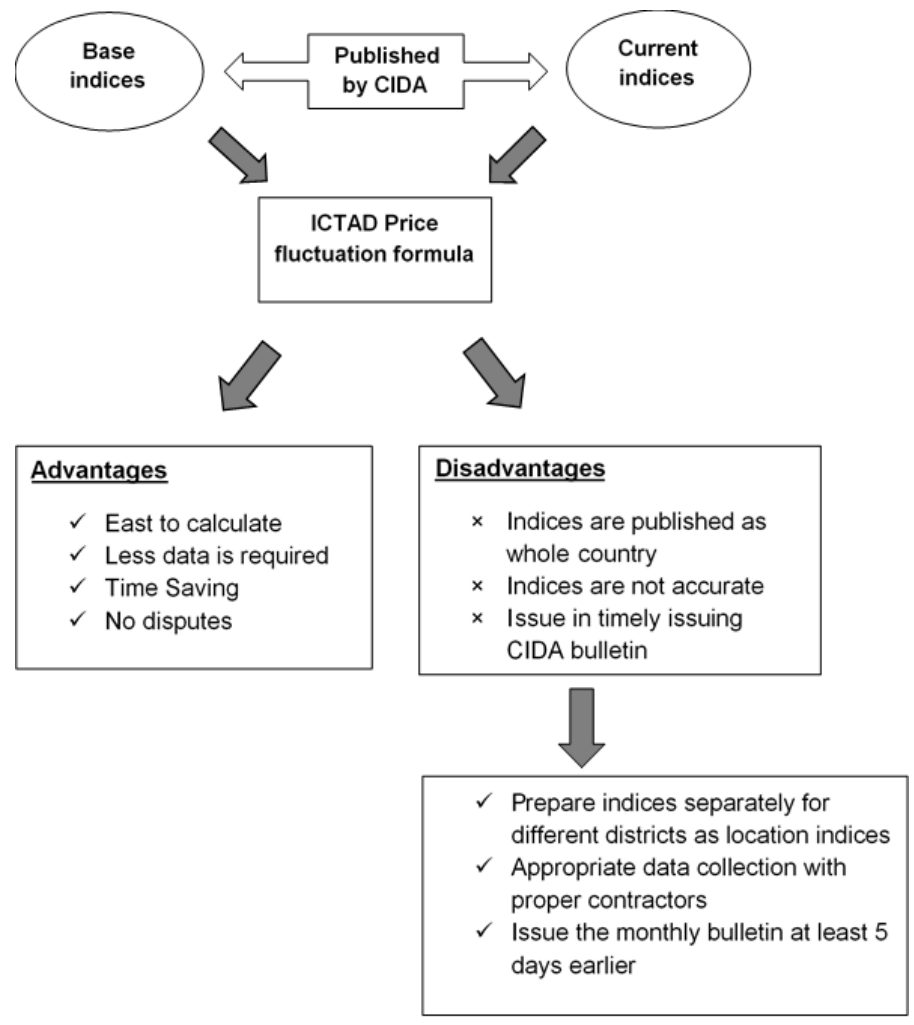

Figure 1: Summary of the knowledge gained 


\section{CONCLUSIONS, RECOMMENDATIONS AND LIMITATIONS}

With reference to the above findings now it can be concluded that there is a difference between the amount calculated with the ICTAD method and actual price fluctuation. The cause of this difference was primarily attributed to issues in price indices. Strong evidence could not be found to conclude the inadequacy of the ICTAD price fluctuation formula.

In light of findings and conclusions, strategies proposed to improve the process of price escalation amount paid to Sri Lankan road construction projects perspective are appropriate data collection using an appreciate sample of contractors in producing price indices, issue the monthly bulletin at least $5^{\text {th }}$ date of the month so that the contractors can use the same month indices, proper location adjustment method or regional indices should be introduced since locational price differences are unavoidable, a competent institute (E.g. IQSSL) should maintain long term price records to calculate base indices and current indices to analyse and adequacy of ICTAD price fluctuation formula should be revisited after attending to above recommendations.

\section{REFERENCES}

Ahenkorah, K., 1994. Reimbursement for changes in construction cost, The Building Economist, 6, pp. 1922.

Ashworth, A., 2001. Contractual procedures in the Construction Industry. New York, Longman, $4^{\text {th }}$ ed.

Brook, M., 1998. Estimating and Tendering for Construction Work. Great Britain, Reed educational and professional publishing Ltd, $2^{\text {nd }}$ ed.

Chandrasena, H.D., 2005. Application of the ICTAD formula for computation of price variation in construction contracts a consultant's point of view, $4^{\text {th }}$ of May 2005 ICTAD auditorium. Colombo: ICTAD, pp. 1-3.

Cook, A.E., 1991. Construction Tendering. London: Batsford Ltd.

Dawood, N.N. and Bates, W., 2000. A decision support system specification for out-turn cost and cost escalation in the heavy engineering industry, Engineering, Construction and Architectural Management, 7(4), pp. 330-346.

Franks, J., 1984. Building Subcontract Management. New York: Longman.

Hanna, A.S. and Blair, A.N., 1993. Computerized approach for forecasting the rate of cost escalation. In Computing in Civil and Building Engineering, pp. 401-408. ASCE.

Institute for Construction Training and Development) 2007. standard bidding document procurement of works - Major contracts, Colombo: Institute for Construction Training and Development.

Jayasinghe, S.A.Y.B., Alahakoon, C.S., and Wijewardena, L.S.S., 2015. Sensitivity of the CIDA price fluctuation formula procedure for the true material price fluctuations in construction industry. Journal of Engineering and Technology of the Open University of Sri Lanka (JET-OUSL), 3(1), pp.19-40.

National Procurement Agency, 2006. Procurement Guidelines - 2006 Goods and Works, Colombo: Department of Government Printing.

Ramus J.W., 1981. Contract practice for quantity surveyors. Guildford \& Kings Lynn: Great Britain Biddlers Ltd.

Sendooran, B., 2005. Impact of oil price increases in construction industry. Unpublished dissertation, (B.Sc.). University of Moratuwa.

Suraweera, E.H., 2001. Inflation and dealing with price fluctuation. Unpublished dissertation, (B.Sc.). University of Moratuwa.

Weddikkara. C. and Devapriya, K., 2001, Development and supply trends and construction industry development. The Australian Journal of Construction Economics and Building, 1(1), pp. 91-105. 